UDC 378.147::811.111](497.11)

\author{
Anne Katz \\ Education Design Group, USA
}

\title{
LINKING LEARNING AND ASSESSMENT IN CLASSROOM PRACTICE
}

\begin{abstract}
In the language classroom, assessment has long been used to describe and verify students' developing language proficiency. More recently, research has suggested that assessment used to promote learning can have a positive impact on student achievement. This paper explores the theoretical foundation for this claim and its implications for classroom practice. It describes how assessment linked to learning can provide insight into the development of language skills and transform the roles of teachers and students. It concludes with examples drawn from the English Department at the University of Belgrade that illustrate how assessment can be integrated with instruction.
\end{abstract}

Nearly one decade into the $21^{\text {st }}$ century, the role of assessment in language classrooms is changing, expanding from such traditional functions as describing and certifying student proficiency to more student-centered uses that provide richer insight into the development of skills and, along the way, that transform the roles of teachers and students (Rea-Dickins 2008). This paper examines these changes and their potential impact on language classrooms.

Assessment has long served key functions in education. School systems rely on assessment data to address important questions related to student learning as well as to serve accountability functions such as determining the effectiveness of specific programs or services. In the case of foreign language programs, several kinds of assessments customarily provide such information: placement tests guide the selection of candidates for specific services and identify appropriate class levels. Diagnostic tests offer a closer look at students' specific strengths and areas for continued development. Achievement tests describe the amount and range of learning students have developed as a result of instruction both 
during and at the end of school terms. Language proficiency tests brought forth by large-scale testing programs such as the Cambridge ESOL suite of examinations and TOEFL are designed to certify language levels as learners progress in their language development.

More recently, assessment has also been seen as an important tool to supportlearning in the classroom (Black and Wiliam 1998b; Rea-Dickens 2001). For teachers, this linkage of assessment with learning represents a departure from more traditional views that separate assessment from what is considered the teachers' main role - that of instructional leader. In fact, many teachers may harbor misgivings about adopting this new role, often feeling they are ill prepared to take on assessment functions such as monitoring, describing or measuring student learning. The following vignette illustrates some of the concerns teachers bring to the table when considering how to adapt their practice to include assessment.

Teachers who work in a private language school have gathered for a workshop on developing assessments. As a starting exercise, they've thought about their previous experiences with assessment. As they share their reflections with others, a theme quickly emerges. Most of the talk centers on why they do not feel comfortable with assessment. Here are some of their concerns:

- Most of us lack knowledge or training.

- We feel that books about assessment aren't interesting or relevant because the focus is on theory rather than application.

- We feel like we are being underestimated.

- We teach using a communicative approach and don't think testing fits with our approach.

The teachers in this vignette voice a concern, common to many language teachers, that neither their pre-service training programs nor their in-service professional development activities have prepared them to incorporate assessments into the stream of classroom activities. In addition to illuminating the essential discomfort many teachers feel towards assessment, the last bullet highlights an important insight from teachers regarding the relationship between assessment and learning that for assessment to be useful in the classroom, it must be congruent with instruction so as to ensure that the information collected is appropriate and relevant to students' learning. It is this linkage between assessment and learning that can transform classrooms, helping teachers develop more useful tools for tapping into student learning and changing the nature of teacher and student roles in assessment. 
A. Katz: Linking Learning and Assessment in Classroom Practice

\section{Emerging views of assessment in school}

In many classrooms that continue to conform to traditional notions of how languages are learned and taught, instruction and assessment are conceptualized as separate activities within the stream of classroom events. The teacher delivers instruction and folds in the occasional test. While teachers may design some of these informal tools, these assessments often are provided by outside agencies or departments or included as ancillary materials accompanying class textbooks and take the form of traditional tests found across subject areas: multiplechoice, short answer, fill-in-the-blank, essays, translations, and the like. However, in the emerging assessment culture (Inbar-Louie 2007) of the $21^{\text {st }}$ century, educators are turning from the use of such traditional test formats to a broader range of assessments, ones that can be linked to and support learning. The push for change has emerged as current theories of learning have focused educators' attention on describing the processes students engage in as well as the products of their efforts as they tackle classroom tasks, interact with other students and the teacher, and work through assignments. Shepard (2000) identifies the following principles underlying new forms of classroom assessment.

- The use of challenging tasks to elicit higher order thinking

- A focus on learning processes as well as learning outcomes

- An on-going process, integrated with instruction

- Expectations visible to students

- Students active in evaluating their own work

- Used to evaluate teaching as well as student learning (p. 10)

Together, these principles inform an approach to assessment that has ushered in a range of assessment types that go well beyond traditional paper and pencil tests at the end of a segment or unit of instruction.

\section{Assessment in the language classroom}

With the advent of task-based and communicative approaches to language teaching has come the use of alternative approaches to traditional testing (Brown 2004). As students engage in showing what they can do with language - writing essays, carrying out role-plays, listening to podcasts, arguing points of view - teachers must implement alternate methods of capturing these performances, for example, through teacher notes, rubrics 
and scoring guides. Students have joined teachers in both collecting and analyzing language performance data through self- and peer-assessments. Figure 1 compares features of traditional and communicative language testing.

\begin{tabular}{|c|c|}
\hline Traditional language testing & Communicative language testing \\
\hline $\begin{array}{l}\text { - Focus on language form } \\
\text { - Learner produces isolated bits of } \\
\text { language that can be scored as right or } \\
\text { wrong } \\
\text { - Decontextualized test tasks focused on } \\
\text { the right answer } \\
\text { - Oriented to product } \\
\text { - Highly objective scoring }\end{array}$ & $\begin{array}{l}\text { - Focus on the total communicative } \\
\text { effect } \\
\text { - Draws on several language skill areas } \\
\text { - Draws on context of the language text } \\
\text { - Open-ended, creative answers } \\
\text { - Oriented to process } \\
\text { - Clear criteria for scoring }\end{array}$ \\
\hline
\end{tabular}

Figure 1: A comparison of traditional and communicative language testing

(Katz 2008, p. 620)

In addition to changing how assessment data are collected, emerging practices in classroom assessment have sharpened the focus on what will be assessed by linking assessment to learning. In arguing for a more constructivist perspective for assessment, Broadfoot (2005) points out:

Whilst certification and selection, monitoring and accountability are also legitimate and important purposes of assessment, the most important of all must be its role in helping or hindering learning since this is the primary purpose of education. (p. 124)

For teachers and students in language classrooms, this function of assessment to support learning is appealing since it emphasizes the usefulness of assessment information in informing decision-making about teaching and learning. The assessment literature has described assessment linked to learning in two ways.

Aligning assessment to instructional targets. A shared understanding of teaching and learning targets leads to transparency for all stakeholders in terms of identifying needs, determining learning objectives, choosing materials, selecting instructional approaches, and developing assessments. A common set of criteria that describe targeted language outcomes provides an explicit basis for linking assessment to instruction within a 
coherent teaching-learning system both at macro and micro levels. Such systems using shared criteria can take several forms as the following examples at the educational macro level suggest.

In Australia, clear statements of learning objectives derived from learner needs analyses were the starting point for developing criterionreferenced assessments and for designing classroom instruction used in Adult Migrant English Programs across the country (Brindley 1989). Because of the shared criteria, local programs were able to develop common expectations for student outcomes and thus devise instructional approaches and assessments to support learners in developing their language skills.

The Common European Framework of Reference for Languages (CEFR) provides a set of reference levels of language proficiency that act to link language learning, teaching and assessment through descriptions of the knowledge and skills learners must develop to communicate effectively. From this framework, language educators produce language syllabi, curriculum guidelines, assessments, and learning materials (Council of Europe, 2001).

In the US as well as increasing numbers of other countries, standards form the basis for designing educational delivery systems that include targeted learning outcomes as well as assessments to measure students' progress in achieving those outcomes. In one example, English language performance standards describe what learners should know and be able to do with language in various academic content areas such as mathematics, language arts, science and social studies (TESOL 2006). These standards provide a basis for developing curricula, including assessments, to meet the needs of school age English learners (Gottlieb, Katz \& Ernst-Slavit 2009).

At the micro level, in language classrooms, when tests or other forms of assessment are designed so that they are aligned with learning goals and objectives, the data collected from such tools provide direct evidence of students' progress in reaching instructional targets. Figure 2 is an example of a simple alignment chart that shows the relationship across learning objectives, classroom activities, and possible assessments.

Notice that students as well as teachers engage in tracking student progress in meeting the language objective. With a planning tool such as this one, teachers can ensure that assessment data related to important learning targets are collected across the period of instruction. 


\begin{tabular}{|l|l|l|}
\hline $\begin{array}{l}\text { Learning } \\
\text { objective }\end{array}$ & Classroom activity & \multicolumn{1}{c|}{ Assessment tool } \\
\hline $\begin{array}{l}\text { Students } \\
\text { will be able } \\
\text { to develop } \\
\text { and } \\
\text { maintain } \\
\text { a "Lexical" } \\
\begin{array}{l}\text { vocabulary } \\
\text { notebook. }\end{array}\end{array}$ & $\begin{array}{l}\text { Students will } \\
\text { create flash cards } \\
\text { from their own } \\
\text { notebooks using } \\
\text { lexical chunks. } \\
\text { On one side is the } \\
\text { chunk on the other } \\
\text { side is a picture or } \\
\text { mnemonic device. }\end{array}$ & $\begin{array}{l}\text { 1. Two Parts: } \\
\text { A. Students will race against the clock } \\
\text { and see how many cards they can } \\
\text { name in a minute. Every week they } \\
\text { will measure themselves against } \\
\text { their previous "score" and against } \\
\text { the "scores" of their peers. } \\
\text { B. Students will fill-in a self- } \\
\text { assessment form. }\end{array}$ \\
\hline
\end{tabular}

Figure 2: Alignment chart linking assessment with learning ${ }^{11}$

Integrating assessment with learning. According to current thinking, more diverse assessment tools and more frequent collection of information about student performances provide richer insight into understanding the process of developing language skills as well as measuring learning that is taking place. The phrase "formative assessment" has been widely used to refer to the array of informal assessments used by classroom teachers to help students develop their language skills by providing feedback on their performances. The aim with such an approach is not merely to classify types of assessment tools but rather to describe how assessment can be used to take action about learning. Another more recently introduced phrase related to assessment integrated with learning is "assessment for learning" (Assessment Reform Group, 2002), often used in juxtaposition with assessment of learning. Both "formative assessment" and "assessment for learning" suggest that assessment can be a means to promote learning, not only to describe or monitor it.

Research evidence supports the claim that assessment that is used to promote learning leads to improvements in student attainment. In a review of 250 studies of assessment practices in the UK in such subjects as mathematics and science, Black and Wiliam (1998a) found that both lower and higher achieving students benefited from classroom practices that provided students with feedback on their performances. This feedback has an impact when it is used in some way to improve student

\footnotetext{
${ }^{11}$ This alignment chart was created by Jeff Puccini as part of the requirement for the Curriculum Development and Assessment course at SIT Graduate Institute.
} 
learning, for example, by teachers adjusting their instruction or students adjusting their learning tactics (Popham 2009). It is useful to note is that such feedback can involve not only teacher to student interaction, but also student-to-student interaction during peer assessment.

\section{Applying assessment linked to learning to the classroom}

Classroom assessment can provide both learners and teachers with useful information about learning and, if well-designed, can even support the development of language skills. Black and Wiliams (1998a) identify two actions that form the core of formative assessment: first, the learner perceives a gap between the present state of knowledge, understanding or skill and the desired target level, and second, the learner takes an action to close the gap and reach the desired target level. The teacher's task, then, is to design assessments that can achieve these actions. Clearly, these actions require a reformulation of the learner and teacher roles within the classroom and a more explicit focus on learning aims that is shared by both teachers and students. Harlen and Winter (2004) describe several characteristics of classroom assessment that can benefit learning:

- Information is gathered about both the processes and products of learning

- This information is used to adapt teaching and learning environments and provide learners with feedback that will help them improve their performances and learn

- Learners and teachers have a shared understanding of the learning goals for activities in the classroom

- Learners are involved in assessing their work through self- and peer-assessments

- Learners are active participants in their learning.

\section{Practice in action: the English Department at the University of Belgrade}

The English program at the University of Belgrade has developed assessment practices in line with an approach that is linked to learning. These practices are part of a larger reform effort to bring instruction and assessment in line with specific learning outcomes and language competences as outlined in the Bologna Declaration. At the program 
level, faculty are using the language proficiency levels from the Common European Framework of Reference (CEFR) as a common set of criteria to describe students' developing communicative competence in English. The CEFR is used at multiple points throughout the English language program. At entry, the proficiency framework sets a baseline level (at B2) for students admitted into the English program. As students move through each year of language classes, the CEFR informs the criteria used by teachers to measure achievement at each level. It is also used to establish exit levels for fluency and proficiency at the end of English language studies. With learning aims that are clearly articulated and shared among students and faculty across the program, all stakeholders can chart language growth over time in the program against a constant measure.

The CEFR also informs the nature of the feedback provided to students. With the CEFR's focus on what learners can do with language, assessments are tailored to examining student performances with scoring rubrics calibrated to the proficiency levels of the CEFR yet reflecting the local context of the English language program. For example, in the case of the writing portion of the Entrance Examination, the scoring guide encompasses a range of writing proficiency from B2 to $\mathrm{C} 1$ as indicated in CEFR descriptions of writing ability. However, the descriptions have been tailored to reflect specific language features by dividing the scoring guide into two main categories: Lexical Resource/Grammar and Coherence/ Task Achievement. In addition to the CEFR, the descriptions were informed by readings of student papers and extensive discussions with faculty who were guided by their knowledge of the instructional program. (See Katz 2008 for a fuller description and analysis of the writing portion of University of Belgrade's Entrance Examination.)

While the Entrance Examination illustrates how assessment can align with learning aims, the use of process writing in the University of Belgrade's English writing program provides an example of how assessment is integrated into and supports learning. Process writing is predicated on the assumption that for each assignment, students will complete multiple drafts and that feedback - either from the teacher or from peers - will help to guide students in developing their writing skills as they work toward an explicit and shared learning target. Rather than viewing writing as a linear progression, teachers who use process writing have students engage in a recursive process. One such process writing approach used in the English program is Six-Trait Writing. The six traits are: Ideas, Organization, Voice, Word Choice, Sentence Fluency, and Conventions. 
The six traits provide the shared explicit learning targets for writing; these are the areas of writing in which students will be expected to develop their skills. The approach to that development comes through a series of steps as they engage in producing drafts. For example, before beginning their first draft, students will engage in prewriting exercises such as answering questions, brainstorming, or listing ideas as a means of generating potential content for their first draft. Feedback, perhaps in the form of talk among students as they review their prewriting exercise, helps student writers find their voice and reflect on what they plan to say. This is but one point in the writing process at which they can change their focus, amend their approach, add ideas or start on a new path altogether.

Once students begin drafting their ideas into some sort of an organizational structure such as a paragraph or essay, feedback can be provided through scoring rubrics used by teachers or by fellow students. Such rubrics help learners focus on one or more specific aspect or trait of writing. Self-assessment tools can also provide students with criteria for reflecting on their progress so far in turning their ideas into a finished written product. As with the prewriting stage, students use the feedback to make changes, revise thinking, fill holes, bolster main points, and so forth. The drafting and revising stage may encompass one or more drafts depending on the assignment and time available. By the end of this recursive process, students will have produced at least two drafts of their writing and worked on developing their skills as writers. Through interactive feedback, students will have moved closer to the targeted learning aims for the class.

\section{Conclusion}

Assessment belongs in the classroom as an important resource for teachers who work diligently with their students to develop communicative language skills. As much of the current assessment literature suggests, assessment can both reflect and impact learning in useful ways. There are, of course, issues that must be considered in any attempt to implement such an approach.

- What is useful feedback? The key to much of the success of the formative assessment found to be effective in the Black and Wiliams' study was in the nature of the feedback provided to students. Several studies have begun to examine the characteristics of useful feedback and to suggest that careful 
thought be given to how it is structured if it is to support learning and provide beneficial washback (Leung and Mohan 2004; ReaDickins 2001). For example, Lyster and Mori (2006) in looking at teacher-student interaction related to students' oral production in French and Japanese immersion classrooms, found that students varied in their ability to use teacher feedback and that contrary to expectations effective feedback was inversely related to the type of instructional orientation in the classroom.

- Are teachers prepared to implement new assessment approaches? Teachers are critical in implementing new assessment approaches as they adapt them to local instructional contexts and to the needs and language levels of their students (Colby-Kelly and Turner 2007; Inbar-Louie 2008). As with any innovation for the classroom, however, teachers require professional development to ensure they have developed the theoretical knowledge and the skills to carry out new ideas and approaches. As programs consider whether or not they will take on assessment innovations, they must also reflect on how they will support teachers by providing staff meeting time, opportunities to collaborate with one another, and necessary resources.

- How receptive are students to new forms of assessment? Students, like their teachers, are the product of years of traditional classroom instruction. Thus, they have expectations about their role and that of their teachers in the learning process. Similarly, their understanding of assessment has been formed by their educational experiences. When teachers attempt to change the rules - engage students in taking responsibility for learning and in reflecting on that learning through self- and peer-assessments - students may not react favorably, feeling uncomfortable or lacking confidence in the role of assessor, especially of their peers' performances (Cheng and Warren 2005). Certainly, developing a supportive classroom climate and engaging students in developing and using assessment criteria may help students develop more confidence in using such assessment tools.

New uses for assessment provide both opportunities and challenges as we reconsider expectations for how learning takes place in the classroom. For those changes to become effective and useful additions to our traditional notions of language classrooms, we will need to reflect on how they can 
A. Katz: Linking Learning and Assessment in Classroom Practice

be integrated into local contexts and become part of the shared practice of language teachers and learners.

\section{References}

Assessment Reform Group. (2002). Assessment for learning: Ten principles. http://arg.educ.cam.ac.uk/CIE3.pdf.

Black, P. and D. Wiliam (1998a). Assessment and classroom learning. Assessment in Education 5: 7-68.

Black, P. and D. Wiliam (1998b). Inside the black box: Raising standards through classroom assessment. Phi Delta Kappan International. www. pdkintl.org/kappan/kbla9810.htm

Brindley, G. (1989). Assessing Achievement in the Learner-centered Curriculum. Sydney, Australia: National Centre for English Language Teaching and Research.

Broadfoot, P. (2005). Dark alleys and blind bends: Testing the language of learning. Language Testing 22 (2): 123-141.

Brown, H. D. (2004). Language Assessment: Principles and Classroom Practices. White Plains, NY: Pearson Education.

Cheng, W. and M. Warren (2005). Peer assessment of language proficiency. Language Testing 22 (1): 93-121.

Colby-Kelly, C. and C. E. Turner (2007). AFL research in the L2 classroom and evidence of usefulness: Taking formative assessment to the next level. The Canadian Modern Language Review 64 (1): 9-38.

Council of Europe (2001). Common European Framework of Reference for Languages: Learning, teaching, assessment. Cambridge: Cambridge University Press.

Gottlieb, M., Katz, A. and G. Ernst-Slavit (2009). Paper to practice: Using the TESOL English language proficiency standards in preK-12 classrooms. Alexandria, VA: TESOL.

Harlen, W. and J. Winter (2004). The development of assessment for learning: Learning from the case of science and mathematics. Language Testing 21 (3): 390-408.

Inbar-Louie, 0. (2008). Language assessment culture. In: E. Shohamy and N. H. Hornberger (eds.), Encyclopedia of Language and Education, Volume 7. Language Testing and Assessment. New York: Springer. 285299. 
Katz, A. (2008). Changing the culture of assessment: Redefining proficiency. In: K. Rasulić and I. T. Milošević (eds.), ELLSSAC Proceedings, Volume 1. Belgrade: Faculty of Philology, University of Belgrade. 615-629.

Leung, C. and B. Mohan (2004). Teacher formative assessment and talk in classroom contexts: Assessment as discourse and assessment of discourse. Language Testing 21 (3): 335-359.

Lyster, R. and H. Mori (2006). Interactional feedback and instructional counterbalance. Studies in Second Language Acquisition 28: 269-300.

Popham, W. J. (2009). A process - Not a test. Educational Leadership 66 (7): 85-86.

Rea-Dickins P. (2001). Mirror, mirror on the wall: Identifying processes of classroom assessment. Language Testing 18 (4): 429-462.

Rea-Dickins P. (2008). Classroom-based language assessment. In: E. Shohamy and N. H. Hornberger (eds.), Encyclopedia of Language and Education, Volume 7, Language Testing and Assessment. New York: Springer. 257-271.

Shepard, L. (2000). The Role of Classroom Assessment in Teaching and Learning. Washington, DC: Center for Research on Education, Diversity and Excellence/Cener for Applied Linguistics.

Teachers of English to Speakers of Other Languages. (2006). PreK-12 English language proficiency standards. Alexandria, VA: Author. 